\title{
FOSSIL VERTEBRATES IN THE EASTEND MUSEUM
}

TIM TOKARYK, Earth Sciences, Saskatchewan Museum of Natural History, Wascana Park, Regina, Saskatchewan. S4P 3V7

The fossil vertebrates in the Eastend Museum, Eastend, Saskatchewan, not only have an ancient history of their own, but have also been important in Eastend's history. The small museum, organized and maintained by volunteers, has survived many long years, starting from a collection in the basement of the selftaught curator, H. S. "Corky" Jones and today occupying an old theatre. Living through a flood and continual lack of funds for upgrading, this little museum has survived many setbacks. Credit is due to the numerous volunteers and to Corky Jones for collecting, preparing and maintaining the small but impressive collection of fossil vertebrates.

In 1984 the author (with the approval of the Saskatchewan Museum of Natural History) spent a week in Eastend cataloging and repairing the collection. The following is a checklist of the fossil vertebrates on display.

EDITOR'S NOTE: For those unfamiliar with the symbols $M$ refers to molar teeth, $P$ to premolars, the numbers note the position of the tooth in question, with superscripts referring to the upper jaw, subscripts to the lower. The EM P designation is the paleiontology collection of the Eastend Museum with collection number for each specimen.

\section{CLASS Mammalia}

\section{ORDER Perissodactyla}

FAMILY Brontotheriidae mandible $\mathrm{P}_{4}, \mathrm{M}_{1-3}$ (EM P1.1) left mandible (EM P21.1) humerus (EM P22.1) five horn fragments (EM P30.1,
EM 31.1, EM P32.1, EM 33.1,

EM P34.1)

maxilla fragment (EM P35.1)

scapula (EM P36.1)

three cervical vertebrae (EM P37.1,

EM P38.1, EM P39.1)

complete mandible (EM P40.1)

left mandible (EM P41.1)

fragment of mandible (EM P42.1)

nasal fragment (EM P43.1)

metacarpal (EM P44.1)

two tibiae (EM P45.1, EM P46.1)

fused ulna and radius (EM P47.1)

FAMILY Rhinocerotidae

cervical vertebra (EM P48.1)

Trigonias species (sp.) complete

mandible (EM P49.1)

\section{CLASS Reptilila}

ORDER Ornithischia

FAMILY Hadrosauridae

eight weathered caudal vertebrae

(EM P2.1, EM P3.1, EM P5.1 EM P7.1

- five caudal vertebrae)

three articulated caudal vertebrae

(EM P4.1)

four articulated caudal vertebrae

(EM P6.1)

two metapodial bones (EM P11.1,

EM P12.1)

FAMILY Ceratopsidae

dorsal vertebra (EM P10.1)

cast of a scapulacoracoid (EM P14.1)

Triceratops sp. partial skull (EM P15.1)

portion of a supraorbital horncore

(EM P19.1)

Torosaurus sp. frill (EM P16.1)

FAMILY Thescelosauridae

lower limb (EM P8.1)

ORDER Saurischia 
FAMILY Tyrannosauridae

caudal vertebra (EM P23.1)

distal end of a metapodial (EM P24.1)

ORDER Eosuchia

FAMILY Champsosauridae

Champsosaurus sp. dorsal vertebra

(EM P17.1)

ORDER Chelonia

FAMILY Trionychidae
Aspideretes sp. nearly complete carapace (EM P20.1)

shell fragment (EM P18.1)

FAMILY Dermatemydidae

Basilemys sp. partial carapace (EM P25.1) fragment of a shell (EM P26.1)

ORDER Sauropterygia

FAMILY Plesiodauridae vertebra centrum (EM P27.1)

CORRECTION to Collecting Vertebrate Palaeontological Specimens in Saskatchewan

TIM TOKARYK, Earth Sciences Department Saskatchewan Museum of Natural History, Wascana Park, Regina, Saskatchewan. S4P 3V7

In the June, 1984 Issue of Blue Jay [42(2):75-76] I authored an article on the legality of collecting fossil vertebrates in Saskatchewan. Recently, I received word from Pat Froese of the Heritage Conservation Division that there should be a few corrections:

1) The Heritage Property Act was passed November 28, 1980, not 1979

(2 In 1982 the deadline for registration was extended to November 27, 1985

3) Recently the act was amended to omit the confiscation of non-registered items. Section 66(2) now reads "All archaeological or vertebrate palaeontological objects found in or taken from the land of Saskatchewan other than those mentioned in subsection (1) are to be registered with the Minister on or before November 27, 1985.

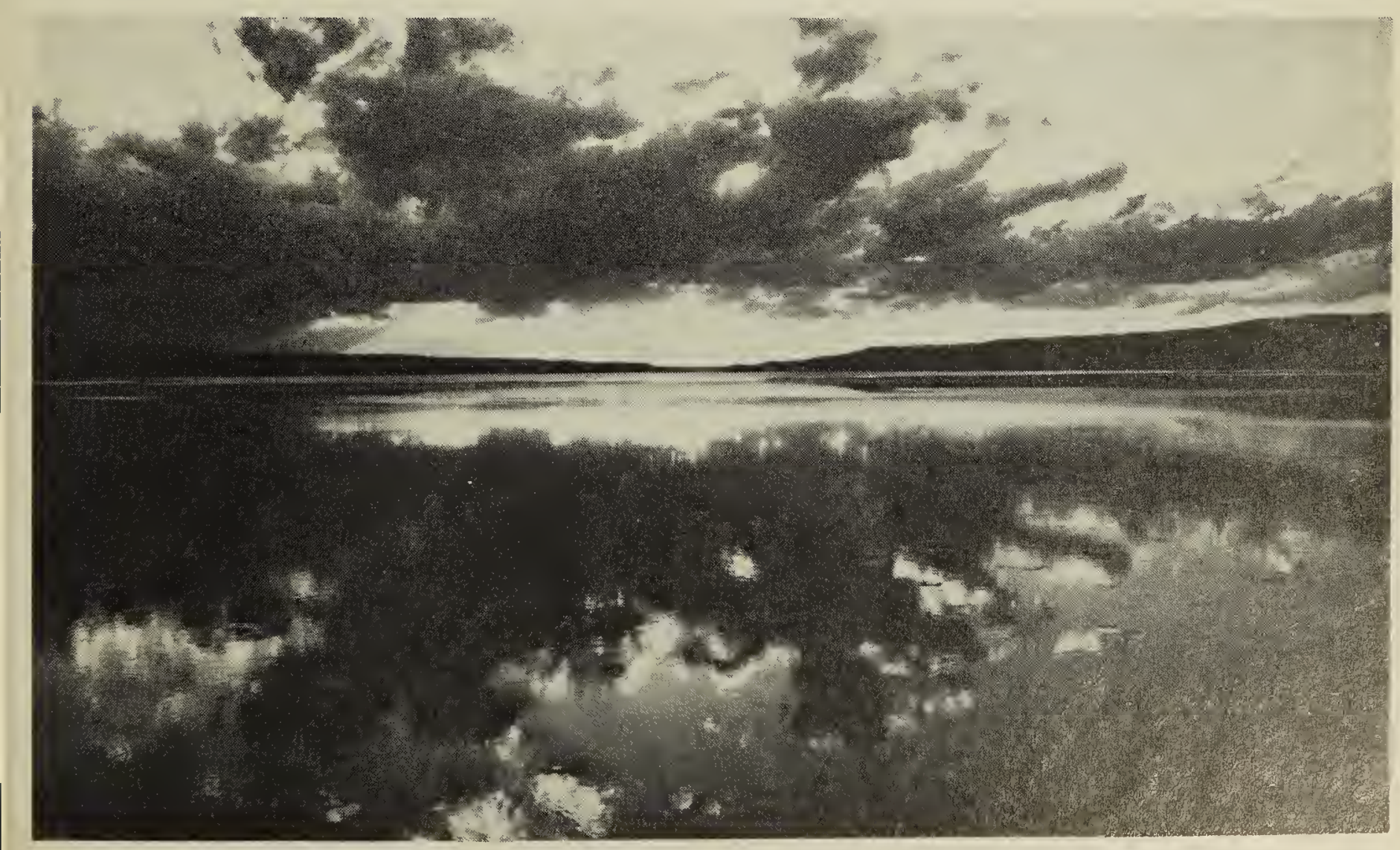

